\title{
Relationships and Partnerships in Community- Campus Engagement: Evolving Inquiry and Practice
}

Lori Kniffin

Fort Hays State University, USA

Jasmina Camo-Biogradlija

University of Michigan, USA

Mary F. Price

Indiana University Purdue University Indianapolis, USA

Emily Kohl

Rockbridge Area Relief Association, USA

Jamie Williams

James Madison University, USA

Alessandra Del Conte Dickovick

Washington and Lee University, USA

Jamie Goodwin

Wheaton College, USA

Kristi V. Johnson

North Carolina Central University, USA

Patti H. Clayton

PHC Ventures, USA

Robert G. Bringle

Indiana University Purdue University Indianapolis, USA

\section{Recommended Citation:}




\title{
Relationships and Partnerships in Community-Campus Engagement: Evolving Inquiry and Practice
}

\author{
Lori Kniffin \\ Fort Hays State University, USA \\ Jasmina Camo-Biogradlija \\ University of Michigan, USA \\ Mary F. Price \\ Indiana University Purdue University Indianapolis, USA \\ Emily Kohl \\ Rockbridge Area Relief Association, USA \\ Jamie Williams \\ James Madison University, USA \\ Alessandra Del Conte Dickovick \\ Washington and Lee University, USA \\ Jamie Goodwin \\ Wheaton College, USA \\ Kristi V. Johnson \\ North Carolina Central University, USA \\ Patti H. Clayton \\ PHC Ventures, USA \\ Robert G. Bringle \\ Indiana University Purdue University Indianapolis, USA
}

Inquiry and practice related to community-campus partnerships are ever evolving, with significant current momentum toward democratic engagement. To inform the ongoing development of associated practitioner scholarship, we examine the development of a tool for assessing the quality of community-campus relationships, the Transformational Relationship Evaluation Scale (TRES), as a microcosm of some underlying dynamics in previous and current work. After an overview of its conceptual foundations, we present TRES, review examples of its uses across multiple contexts, and share lessons learned from critical reflection on those uses along with associated implications for the future development of such tools. Subsequent discussion focuses on shifts toward conceptualizing both partnerships themselves and processes of inquiring into them in terms of systems and co-creation. Seeking to support readers in operationalizing democratic engagement in their inquiry and practice, we share conceptual frameworks, tangible tools, guiding questions for research, and reflective critique on our experience as practitioner-scholars of partnerships.

Keywords: assessment, democratic engagement, partnerships, relationships, service-learning, transformation 


\section{Relaciones de colaboración y alianzas comunidad-campus: Evolución de la investigación y la práctica}

La investigación y la práctica relacionadas con las alianzas comunidad-campus están en constante evolución, con un notable impulso actual hacia el compromiso democrático. Con el objetivo de fundamentar el estado en que se encuentran las becas para profesionales asociados, hemos examinado el desarrollo de una herramienta llamada TRES (Escala de Evaluación de Relaciones Transformacionales, según siglas en inglés), que evalúa la calidad de las alianzas comunidad-campus como un microcosmos de algunas de las dinámicas subyacentes en investigaciones anteriores y actuales. Después de una descripción general de sus fundamentos conceptuales, hicimos la presentación de TRES, revisando ejemplos de sus usos en múltiples contextos y compartiendo experiencias aprendidas en la reflexión crítica acerca de dichos usos, además de analizar las implicaciones asociadas en el desarrollo futuro de este tipo de herramientas. La discusión posterior se centra en los cambios a efectuarse en aras de una conceptualización de estas alianzas y de los procesos de investigación que se establecen entre ellas, en términos de sistemas y de creación compartida. Hemos intercambiado marcos conceptuales, herramientas tangibles, preguntas de orientación para la investigación y críticas reflexivas acerca de nuestra propia experiencia como profesionales académicos en estas alianzas, con el fin de ayudar a los lectores a poner en funcionamiento el compromiso democrático, tanto en la investigación como en la práctica.

Palabras clave: evaluación, compromiso democrático, alianzas, aprendizaje en servicio, transformación

Editors' Note: Translation by Yamilet Hernandez Department of English and Foreign Languages Barry University, USA

Service-learning and community/civic engagement (SLCE) explicitly place importance on communitycampus relationships and partnerships, recognizing that they are, or should be, at the heart of all engagement activities. Their centrality is a theme running through several decades of work by SLCE practitioner-scholars (the term we use to refer to any individuals who partner in SLCE with a spirit of inquiry and who connect their learning with that of others so as to advance knowledge and practice). The conferences and publications of the International Association for Research on Service-Learning and Community Engagement have for two decades encouraged, supported, and disseminated such work through specific tracks on community partnerships. Additionally, illustrating a useful approach to organizing ongoing inquiry, three chapters in Research on Service Learning: Conceptual Frameworks and Assessment (Clayton et al., 2013) - focused on interpersonal relationships (Bringle \& Clayton, 2013), interorganizational partnerships (Janke, 2013), and student partnerships (Jacoby, 2013)—proposed agendas and questions for future research that emerge from critiques of previous research and from possibilities suggested by a range of theoretical and conceptual frameworks and measurement approaches. Recent works that focus on building capacities of SLCE units and staff-for example, Diving Deep in Community Engagement (McReynolds \& Shields, 2015) and the Community Engagement Professional in Higher Education (Dostilio, 2017) — conceptualize innovation in partnership work as one of the defining characteristics and priorities of the role of SLCE professionals.

More specifically, the past decade has witnessed significant interest in examining SLCE relationships and partnerships through the lens of the distinction between technocratic and democratic engagement as articulated in the Democratic Engagement White Paper (Saltmarsh et al., 2009). That piece called community-campus engagement away from the dominant model of academic expert-centered, deficitbased, hierarchical relationships and toward partnerships grounded in democratic values and commitments that position everyone involved as co-educators, co-learners, and co-generators of knowledge and practice and that foreground an asset-based orientation in which power and responsibility are shared by all partners. Democratic engagement is characterized by relationships that transcend exchange-based transactions. Its insistence on co-creation-with the many associated shifts in perspective, identity, norms, and behaviors - gives it transformative potential (transformative of self, others, community organizations, communities, educational institutions, systems, paradigms). The 
democratic engagement paradigm in SLCE has been further developed through, for example, research on the factors influencing the development of democratically engaged community-campus partnerships (Dostilio, 2014) and research on the perceptions of community partnerships as to the democratic (or not) processes and outcomes of their partnerships with higher education institutions (Muse, 2018).

It is in this environment of democratic engagement - and in recognition of the dearth of tools available for helping practitioner-scholars operationalize commitments to democratic engagement - that the Transformational Relationship Evaluation Scale (TRES) was developed. Its co-creators viewed having approaches to gauge the transactional and transformational dimensions of SLCE relationships and partnerships as key to enacting the paradigm of democratic engagement. Its applicability to both inquiry and practice (discussed in depth in this article) render TRES an especially useful tool for practitionerscholars, who can deploy it for the purposes of examining and deepening partnerships through a democratic lens. Complicating related inquiry and practice is the reality that relationships operate at multiple levels and are dynamic, by their very nature (e.g., movement through various phases), and even more so when understood and undertaken in the spirit of democratic engagement, with its complex interactions among diverse individuals and across distinct organizational, educational, economic, political, and cultural contexts. Inquiries into relationships and the tools used to deepen understanding and practice can, have, and need to expand to reflect both the changing contexts within which relationships form and work is undertaken and the ever-growing set of relevant conceptual and theoretical frameworks available.

Establishing and sustaining democratic relationships and partnerships require a commitment to ongoing learning - about particular relationships and relationship processes generally. TRES is an example of a tool that can support and inform such learning. SLCE practitioner-scholars must continue to build capacities to inquire into and learn about relationships. Such inquiry may take many forms including, for example, the typology we use in this article: (a) individual or collaborative reflection on the practice of relationships (e.g., to deepen mutual understanding among partners, to guide continual enhancement of partnership processes); (b) assessment of the quality or the impact of relationships (e.g., to inform program planning, to contribute information in reporting processes, to explore the connections between relationship quality and impact); and (c) research into the conditions that support and hinder relationships flourishing, the factors that influence whether they deepen over time, and the reasons underlying their intended and unintended contributions to the outcomes of various constituencies (e.g., to contribute to a growing knowledge base, to develop and refine tools for inquiry, to evaluate relationship theories).

In this article, we begin by describing the conceptual foundations that led to the development of TRES - including key contributions that define and refine our conceptualization of relationships and partnerships. Then we present two iterations of TRES and outline nine ways practitioner-scholars have implemented it. All the coauthors of this article - doctoral students, center staff, researchers, consultants, and faculty-have some connection to the evolution of TRES, including using it as a tool for investigating the quality of relationships in general and co-created partnerships in particular. We draw on those first-hand experiences to provide an analysis of lessons learned from using TRES and explore implications for further inquiry and practice. Lastly, because we view TRES as a microcosm of the ongoing evolution of inquiry and practice, we examine implications of emerging shifts in thinking about both partnerships (our core construct) and inquiry (our core process) beyond this tool. This article may be useful to any practitioner-scholars who are involved in community-campus partnerships, including those who want to assess and enhance the practice of relationships and those who seek to understand and advance conceptualizations of relationships, partnerships, and democratic engagement. In the spirit of praxis, this article includes tangible tools that can be used in professional development contexts and in assessment practices while also sharing significant conceptual work to strengthen democratic engagement. 


\section{The Origins of TRES}

Twenty years ago, the Michigan Journal of Community Service Learning published a special issue focused on strategic directions for research. Cruz and Giles (2000) asked, "Where's the community in service-learning research?" and examined a variety of challenges to evaluating community outcomes of SLCE, one of which was a lack of clarity and consensus on what is meant by "community." They suggested that research focus on partnerships themselves and that partners be involved in generating knowledge about partnerships. Bringle and Hatcher (2002) agreed that the quality of community-campus relationships is key to the work of SLCE and explored "how the nature of campus-community partnerships can be analogous to and draw from the study of interpersonal relationships" (p. 504). They also indicated that, as relationships develop and are maintained, some may be framed primarily in terms of equitable investments and outcomes whereas others may "move from an exclusively exchange orientation to a more communal one that considers joint outcomes across a long-term perspective" ( $p$. 511). Building on this foundation, Bringle et al. (2009) offered three contributions to the study of SLCE relationships in general and the development and uses of TRES in particular. We provide a brief overview by way of establishing how our understanding of relationships informed TRES and, in turn, how that understanding is informed by the evolution of conceptual underpinnings of the original tool.

\section{Distinguishing Between Relationships and Partnerships}

First, Bringle et al. (2009) noted a distinction between "relationship" and "partnership," with relationship being a broad category and partnership denoting a subset of relationships that have special attributes: closeness, equity, and integrity. Thus, all SLCE activities involve relationships, but these may or may not be partnerships (see Figure 1).

\section{Figure 1}

The Nature of Types of Relationships

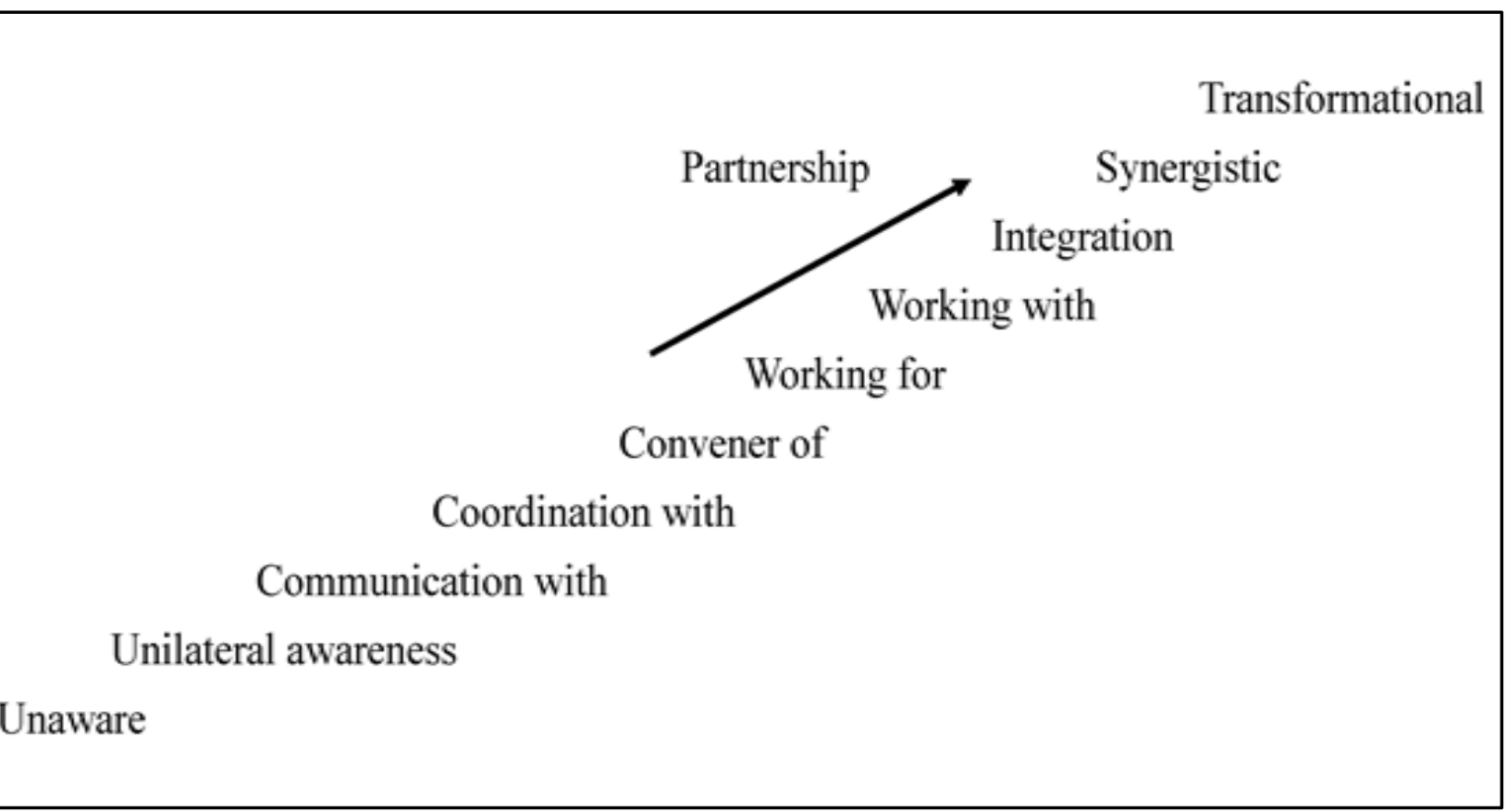

Note. Bringle et al. (2009) 
Relatedly, this work has confronted two different uses of the term partnership: (a) one that refers to relationships with particular attributes (i.e., the three just noted) and (b) one that refers to a structured, enduring association of individuals, groups, and organizations that engages in common activity and combines resources to achieve common goals. To provide further clarity on this issue, we recommend the term partnership entity be used to label the latter, and we adopt that practice here. The focus on structure and social ties explicit in (b) speaks to partnerships as not only interpersonal relationships but also expressions of social networks and forms of social structure (e.g., Wasserman \& Robbins, 2012). We recognize that the term network can refer to social ties among two or more individuals or organizations; for the purposes of this article, we have chosen to reserve the term network for those relationships that are more extensive than a triad.

\section{Differentiating the Stakeholders/Constituents in Relationships and Partnerships}

Second, Bringle et al. (2009) suggested that the common framing "community-campus" is too simplistic and monolithic to represent the complexity and variety of the constituencies that form relationships and partnerships in most SLCE activities. They drew on Bringle and Hatcher's (2002) work, which clarified that "campus-community partnerships involve multiple dyadic relationships that create social networks of campus staff, faculty, students, staff from community based organizations, clients of community-based organizations, and residents of various communities" (p. 513), to formalize the SOFAR model (Figure 2).

Figure 2

SOFAR Model of SLCE Relationships and Partnerships

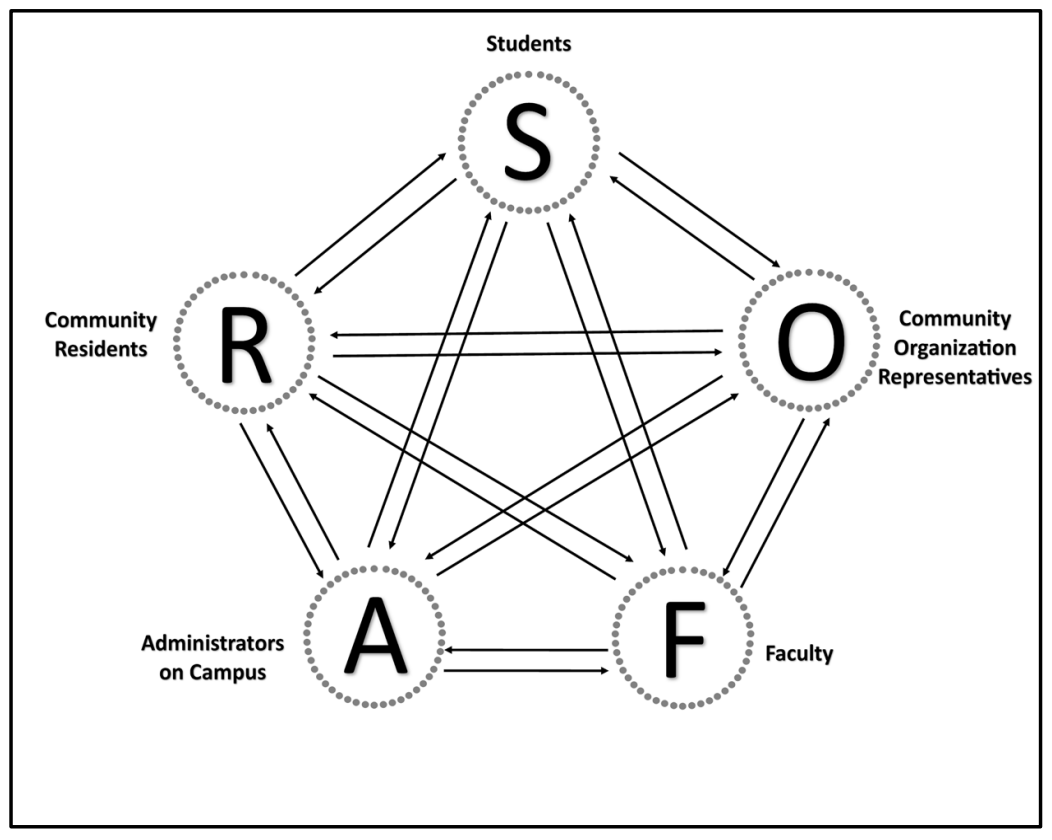

Note. Bringle et al. (2009)

SOFAR illustrates how "community-campus" relationships and partnerships can be differentiated into Organizational staff and Residents/clients (community stakeholders), and Faculty, Students, and institutional Administrative or professional staff on campus (campus stakeholders). SOFAR most explicitly illuminates the dyadic and potentially bi-directional relationships between individuals, but its relevance is not limited to that level of analysis. Bringle et al. (2009) acknowledged that SOFAR is only 
one step in differentiating the most relevant constituencies (i.e., potential partners) in SLCE (e.g., other categories such as funders, municipalities, neighborhood organizations, organizational associations) and that relationships may often be more complex (e.g., relationships within SOFAR categories; networks of relationships that transcend dyads and triads; relationships between organizations, not just individuals, and among organizations and individuals). Figure 3, the next iteration of the SOFAR model, illustrates that dyadic relationships, for example, may occur between and among members of the same category (e.g., between students in an SLCE course) and that those individuals may have relationships to one another and to members of other categories. Furthermore, an individual may be associated with more than one SOFAR category (e.g., an instructor or student may also have an administrative role, be a board member of a community-based organization, and be a resident of the community).

\section{Figure 3}

Extension of the SOFAR Model

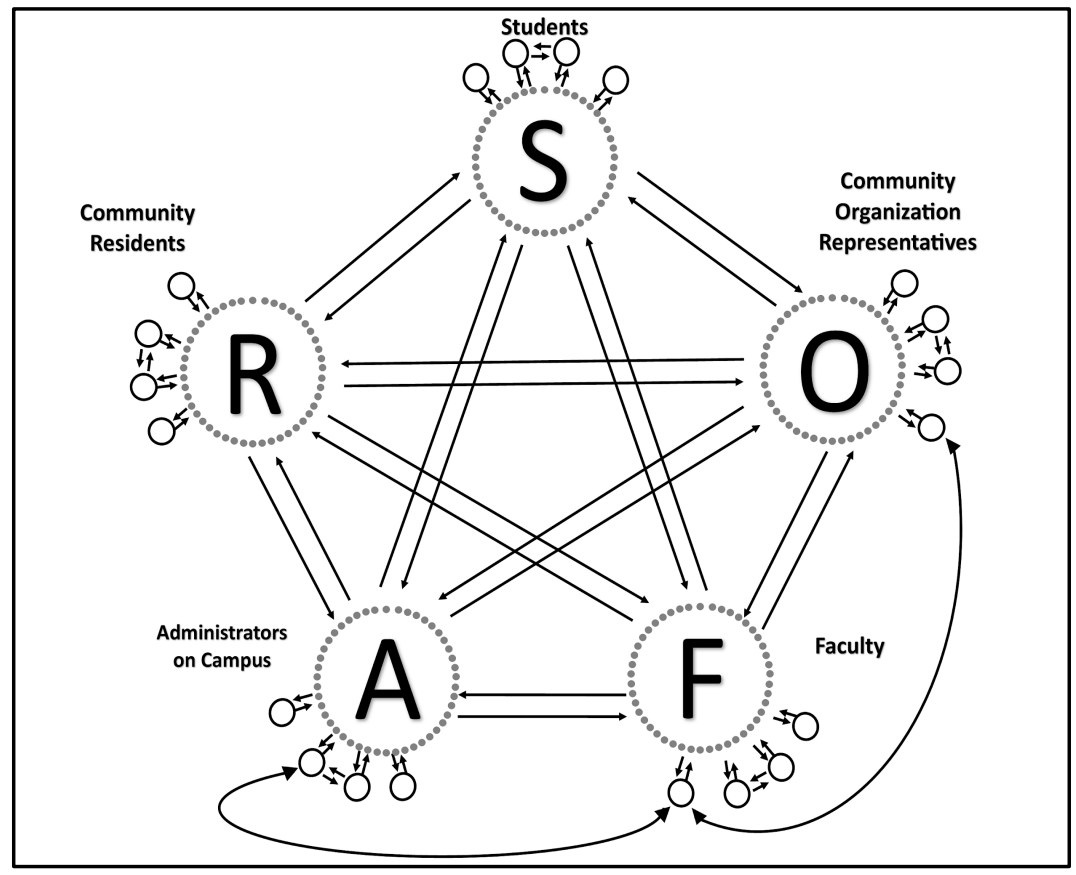

\section{Operationalizing Distinct Paradigms of Relationships and Partnerships}

Third, Bringle et al. (2009) expanded on and operationalized the relationship paradigms Enos and Morton (2003) brought to SLCE with the distinction between transactional and transformational relationships. They posited that relationships can be characterized on an E-T-T continuum: exploitativetransactional-transformational. Transactional relationships aim for outcomes that are net positive (benefits exceed costs) for all members, with interactions grounded in exchanges that are often short-term, close-ended, and context-bound (i.e., concerned with the objectives of a particular activity). In transformational relationships, which are by our definition of partnerships, individuals who do not merely benefit but also grow as they question established norms and take on complex roles, and this may in turn lead to change in the partnerships and systems they are part of as well. Members of transformational relationships adopt longer-term and more open-ended perspectives, their identities are defined at least partly in terms of the partnership and its broader goals, and those goals evolve as new meanings and possibilities emerge. Exploitative relationships - characterized as having net negative outcomes (costs 
exceeding benefits) for at least one member or as including oppressive elements - were added to the continuum in response to early feedback from SLCE practitioners who knew of or experienced such relationships and judged the framework incomplete without them. Relationships may exhibit characteristics associated with multiple points along the E-T-T continuum (e.g., they may be transactional in some aspects and transformational in others), and they may shift in either direction on the continuum across time and across contexts.

Deliberately examining a relationship through the lens of the E-T-T continuum may encourage and enable intentional change, with one or more members taking steps to move the relationship closer to its desired characteristics (whether transactional or transformational, assuming that no one engaged in an SLCE relationship actively intends it to have exploitative elements). Bringle et al. (2009) noted the potential value to members of any SLCE relationship of making visible the perspective of each individual in the relationship (i.e., any constituent of a dyad, triad, network, or partnership entity) concerning the relationship's position on the E-T-T continuum and, in turn, considering appropriate changes and investing in the capacity building needed to make them (e.g., learning or refining skills associated with co-creation). Building on this work, Bringle and Clayton (2013) developed a research agenda for SLCE relationships that invited examination of multiple perspectives on relationships, the nature and qualities of relationships, different measurement strategies, the development of relationships over time, and how any of these issues is related to the impact of the relationships (e.g., outcomes for different constituencies in SOFAR, outcomes for communities more generally, changes in identities).

\section{Summary}

These three contributions provide a backdrop against which further work was conducted to expand conceptualizations of and inquiry into SLCE relationships and partnerships. This work has included delineating some aspects of SLCE relationships; examples that include reflection, assessment, and research to evaluate the usefulness of this work; and reassessment of the strengths and weaknesses of this work. All of this work has been done within the context of aspiring to promote democratic values and processes in SLCE relationships. This provided a basis for operationalizing some of the constructs and exploring some of the uses of them for inquiry and practice.

\section{TRES: A Microcosm of Evolving Inquiry into Relationships and Partnerships}

It is important to make clear that TRES is but one tool, albeit one that can be used in many ways and for multiple purposes, some of which we review below. Furthermore, TRES is one particular type of tool, a scale that can be and has been used in combination with other mechanisms of inquiry. Lessons learned from the evolution of this tool, some of which we consider below, can and should be applied to other approaches, just as work on TRES has been informed by the development, use, and critique of other tools.

\section{TRES}

Bringle and Clayton developed TRES to enable examination of the characteristics of any SLCE relationship in terms of the degree to which it is viewed by its members as exploitive, transactional, or transformational. Offering a finer level of discrimination and enabling more precise assessment of the characteristics of a relationship than the conceptual E-T-T continuum alone, the scale consists of items in nine domains: outcomes, goals, decision-making, resources, conflict, identity formation, power, significance, and satisfaction and change for the better. Item response options for each domain represent points along the E-T-T continuum. TRES is based on the presumption that an examination of the characteristics of the relationship (i.e., the attributes that comprise the nine domains) yields a phenomenologically meaningful (i.e., resonant with experience) summary of the relationship on the E-TT continuum from an individual's perspective.

Table 1 presents two sample items; the full set of items can be found in Clayton et al. (2010). Although the language in the items is that of partnership, TRES is framed to guide respondents to focus 
on interpersonal relationships (some of which may also be partnerships). Instructions for using the scale invite respondents to indicate the current status and the desired status of the relationship in question for each of the nine domains - as a way to enter into exploration of particular changes that might enhance the relationship - although these instructions can be modified to suit the purpose at hand. TRES demonstrated good internal consistency and convergent validity with a simple, nonverbal, visual representation of degrees of closeness (overlapping circles; see Mashek et al., 2007) and a 4-item measure of closeness (Clayton et al., 2010).

Table 1

Sample Domains and Items From TRES

Outcomes of the service-learning partnership

a) There are more costs than benefits for both of us in this partnership

b) One of us benefits but at a cost to the other

c) Neither of us benefits to a significant degree from this partnership, but neither experiences a significant cost either

d) One of us benefits much more than the other, although not at a significant cost to either of us

e) We benefit equally (in terms of getting something we value) from the partnership

f) We benefit equally (in terms of getting something we value) and one of us grows through the partnership

g) We benefit equally (in terms of getting something we value) and both grow through the partnership

h) We benefit equally (in terms of getting something we value) and both grow and the relationship itself grows

i) We benefit equally (in terms of getting something we value) and both grow, the relationship itself grows, and the systems (e.g., organizations) that we are part of become more capable of generating growth because of our partnership

Role of this partnership in work and identity formation

This service-learning partnership

a) Has on balance hindered work for both of us

b) Has on balance hindered work for one of us

c) Has helped one of us to do our work but has no impact on the other's work

d) Has helped both of us to do our work

e) Has helped both of us do our work and has helped define "who I am" for one of us, but not the other

f) Has helped both of us do our work and has helped define "who I am" for both of us

g) Has helped both of us do our work and has helped define "who I am" for both us and has enhanced the ability of one of us to contribute in significant ways through our work

h) Has helped both of us do our work, has helped define "who I am" for both of us, and has enhanced the ability of both of us to contribute in significant ways through our work

The aspiration for TRES was that it would be applicable to all relationships in SOFAR (and beyond) and that it would be useful in both inquiry and practice. Possibilities include, for example, examining relationships between two individuals viewed from either or both individual's perspectives; examining relationships among more than two individuals (e.g., triads, networks); examining dynamics at an organizational level, or any combinations of these. It can be used to examine changes in relationships over time (e.g., perceived status on each of the domains at multiple points in time, as documented at each moment or at a single moment with retrospective and prospective perspectives incorporated) and to 
improve relationships so that they are more aligned with participants' expectations (e.g., through discussions about differences and similarities in ratings from different perspectives).

\section{TRES II}

The evolution of TRES (which we will now label TRES I) into TRES II was driven by all three knowledge sources noted earlier: use-based critique (e.g., by its co-creators in response to its pilot use), promising partnership practices, and literature (e.g., on inter-organizational relationships). The interest of an established democratically engaged partnership entity in reflecting on itself in order to better understand and document its own evolution and transformational nature led its members to TRES I (at the time in the pipeline for 2010 publication), but it was deemed too time-consuming and complex for their purpose. In addition, the focus of TRES I on interpersonal relationships was off-point for their purposes. Clayton, Bringle, and Janke (an SLCE colleague who was bringing work on inter-organizational relationships into SLCE literature) worked with that partnership to modify the presentation, the instructions, and some of the content of TRES I, making it more user friendly while also calling respondents' attention to the dynamics of the partnership entity as a whole. The initial version of TRES II that resulted (Clayton et al., 2009) has been widely used (as discussed in depth below) and also refined into the version we share here (Table 2).

Thus, work on TRES II explicitly broadened the focus of inquiry beyond interpersonal relationships to apply to higher levels of networks (e.g., multi-partner, inter-organizational) as well as partnership entities. Framing language and items refer to "the partnership" as a whole, although modifications to that language allow use at other levels of analysis. TRES I has a variable number of response options across items (see Table 1), which offers the advantage of finer levels of discrimination within the E-T-T continuum but which also complicates some of its uses in both inquiry and practice. Items in TRES II all have the same number of response options, and the description of each option is considerably less complex than in TRES I.

TRES II consists of 10 items related to domains of the partnership entity (or, with modified language, dyads, triads, or networks), including, for example, goals, conflict, decision-making, resources, power, and satisfaction (see Table 2). The scale can be completed by one person, both members of a dyad, multiple individuals, members of a partnership entity, or any combination of these. In addition, some users (including the original partnership entity that helped develop TRES II) have sought ancillary information by including three additional items about the impact (on respondents, their organizations, others) of the partnership entity, each with five response options related to potential transformation.

As with TRES I, TRES II invites perceptions of both current and desired status of relationship characteristics and was designed with the expectation that it would be applicable to all relationships within SOFAR (and beyond), either developing or established, from each constituent's perspective, and for all types of SLCE activities. Although TRES II is not yet a psychometrically validated scale, it does have content validity (i.e., it has a representative and adequate sample of relationship domains on the E-T$\mathrm{T}$ continuum). As illustrated below, it has proven useful in many contexts for studying relationships, structuring reflection on relationships, assessing some of the attributes of particular relationships, conducting research, and guiding practice. 


\section{Table 2}

\section{TRES II Domains and Items}

Instructions: The following survey is focused on a community-campus partnership. There are no right or wrong answers. Please indicate your general impressions about the partnership and select only one alternative that best represents your experience in the partnership. Mark with an "X" the alternative that best characterizes the actual nature of the partnership from your point of view. Mark with an "*" the alternative that best characterizes the desired nature of the partnership from your point of view (if desired is the same as actual, please put " $\mathrm{X}^{*}$ " next to your selection).

1. Goals:
a. The goals of some of the partners are not known and are hampered, and this causes harm.
b. Only some of the partners' goals are acted on, but that is not harmful to anybody.
c. The distinct goals of all the partners are important to and nurtured by the partnership.
d. We share common, integrated, and expanding goals that are "our" goals (not "mine" and "yours" separately).

\section{Conflict:}
a. Conflict remains unacknowledged or is avoided, and this causes harm to the partners.
b. Conflict is acknowledged and partly managed such that underlying issues are unresolved but neither the partners nor partnership is harmed.
c. Conflict is successfully resolved by the partners.
d. Conflict is embraced by the partners as a catalyst to generate new possibilities for the partnership.

\section{Decision-making:}

a. Some of the partners make decisions in ways that do not involve all of us, and those decisions disadvantage at least one of us.

b. Decisions are made in isolation but with consideration of the other partners.

c. Partners make decisions through a means acceptable to all, and the decisions reached serve us individually.

d. Partners carefully weigh possibilities and determine together how decisions are made, and the decisions we make benefit the partnership as well as the individual partners.

4. Resources (e.g., material goods, time, expertise, money):

a. Some partners take resources from others and/or there is no consideration of what is appropriate for each to contribute; some partners are harmed as a result.

b. Some partners contribute resources to and for other partners, who are not thought to have resources to contribute.

c. Partners exchange existing resources for mutual benefit.

d. Investment of resources is equitable (even if unequal, our contributions are proportional to our means), new resources are generated, and resources are understood to be collective (not "mine" and "yours").

\section{Role of this partnership in each partner's work:}

a. The work of some partners is hindered by participating in the partnership.

b. The partnership advances the distinct work of some partners through the contributions of others

c. The distinct work of all partners is advanced through the contributions of others.

d. Partners co-create work that we see as "our" work, and our individual and collective capacity to understand and do the work is enhanced. 
6. Role of this partnership in sense of self (for example, confidence, agency, voice):

a. The sense of self of one or some partners is weakened by participating in the partnership.

b. The partnership contributes to the distinct sense of self of some partners through the contributions of others.

c. The distinct sense of self of all partners is strengthened through the contributions of others

$\mathrm{d}$. The sense of self of all partners is deepened by developing a joint sense of self (as members of the partnership).

\section{Extent and nature of interactions:}

a. Interactions among partners are negative for some of us.

b. Some partners control the extent and nature of interactions, but the intent is for them to be positive.

c. A range of interactions is decided upon with contributions by all partners.

d. The variety of frequent interactions that partners design goes beyond what any of us would otherwise do on our own and support the growth of partners (and the partnership).

8. Power (in other words, the ability to have influence):

a. Some partners are taken advantage of through others' uses of power, and their own power is not recognized.

b. Some partners use their power for the benefit of (some) others as those others have defined it.

c. The power of all partners is combined, and all of us have the power to enhance the equity of power distribution.

d. The joint power of all partners generates new sources of and ways to use power, within each of us and as a partnership.

\section{Outcomes:}

a. This partnership undermines outcomes that matter to some partners.

b. This partnership advances outcomes that matter to some (but not all) partners individually.

c. This partnership enables all partners to attain outcomes that matter to us.

d. This partnership cultivates individual and collective growth while allowing everyone to attain outcomes that are individually and jointly meaningful.

\section{Satisfaction:}

a. Most of us are dissatisfied with this partnership.

b. Most are satisfied with this partnership, but some are dissatisfied.

c. All of us are satisfied with this partnership.

d. Most or all of us are more than satisfied with this partnership; it exceeds our expectations.

Note. Modified from Clayton et al. (2009)

\section{Uses of TRES I and II}

As originally intended and as summarized in Table 3, practitioner-scholars have adopted TRES (the name we will use henceforth in this article to encompass both TRES I and TRES II) to support inquiry and practice over the past decade. The brief description of each example in the table identifies the version of TRES that was used. The version of TRES II that was used in these examples (Clayton et al., 2009) was an earlier version of the one presented in this article (see Table 2); however, they both are similar and consistent with the underlying framework. The table also indicates which SOFAR constituents were involved and how. SOFAR letters separated by arrows indicate the category of the respondents completing the scale; the category of the stakeholder(s) they were referencing when they completed it; 
and whether the responses were unidirectional, bidirectional, or focused on a partnership more broadly. The table indicates for each example one or more inquiry processes (i.e., reflection, assessment, research) and intended purposes (e.g., relationship development, program capacity building/refinement, knowledge generation, tool development). Finally, it provides a few details about each use that highlight significant dimensions of the project, findings gleaned, and unique features.

Table 3

Comparison of Example Uses of TRES

\begin{tabular}{|c|c|c|c|c|}
\hline Examples & $\begin{array}{l}\text { SOFAR } \\
\text { participants }\end{array}$ & $\begin{array}{l}\text { Mode of } \\
\text { inquiry }\end{array}$ & $\begin{array}{l}\text { Purpose(s) } \\
\text { of inquiry }\end{array}$ & Specifics and points of significance \\
\hline \multicolumn{5}{|l|}{ TRES I } \\
\hline $\begin{array}{l}1 \\
\text { Faculty from four } \\
\text { campuses in two } \\
\text { states }\end{array}$ & $\mathrm{F} \rightarrow \mathrm{O}$ & $\begin{array}{l}\text { Reflection } \\
\& \\
\text { Research }\end{array}$ & $\begin{array}{l}\text { Relationship } \\
\text { development } \\
\& \\
\text { Knowledge } \\
\text { generation } \\
\& \\
\text { Tool } \\
\text { development }\end{array}$ & $\begin{array}{l}\text { - Piloted TRES I, at the instigation of } \\
\text { the tool's co-creators; established } \\
\text { evidence for the tool's validity } \\
\text { - Used by } 20 \text { experienced SLCE } \\
\text { faculty as part of a broader, four-part } \\
\text { interview process (in-person and oral } \\
\text { for some; remote and written for } \\
\text { others) to examine their relationships } \\
\text { with a representative from each of } \\
\text { two community organizations } \\
\text { - Piloted only among faculty members } \\
\text { so as not to impose an untested } \\
\text { process on community members-a } \\
\text { choice the investigators would } \\
\text { probably make differently today } \\
\text { - Revealed that many faculty desired } \\
\text { more transformational relationships } \\
\text { than they currently had; current } \\
\text { partnerships were limited by time } \\
\text { constraints and experience in previous } \\
\text { relationships }\end{array}$ \\
\hline $\begin{array}{l}2 \\
\text { Faculty and } \\
\text { community partners } \\
\text { supported by an } \\
\text { SLCE center }\end{array}$ & $\mathrm{F} \leftrightarrow \mathrm{O}$ & Reflection & $\begin{array}{l}\text { Relationship } \\
\text { development }\end{array}$ & $\begin{array}{l}\text { - Served as a professional development } \\
\text { opportunity with faculty and } \\
\text { community partner pairs that placed } \\
\text { equal importance on the experiences } \\
\text { and perspectives of both members }\end{array}$ \\
\hline $\begin{array}{l}3 \\
\text { Faculty and } \\
\text { research staff from } \\
\text { multiple institutions }\end{array}$ & $\mathrm{F} \leftrightarrow \mathrm{O}$ & Research & $\begin{array}{l}\text { Knowledge } \\
\text { generation } \\
\& \\
\text { Relationship } \\
\text { development }\end{array}$ & $\begin{array}{l}\text { - Used by faculty from four institutions } \\
\text { in the Midwest and their community } \\
\text { organization partners } \\
\text { - Attempted to surface conditions and } \\
\text { supports that characterize } \\
\text { transformational partnerships. }\end{array}$ \\
\hline
\end{tabular}




\begin{tabular}{|c|c|c|c|c|}
\hline Examples & $\begin{array}{l}\text { SOFAR } \\
\text { participants }\end{array}$ & $\begin{array}{l}\text { Mode of } \\
\text { inquiry }\end{array}$ & $\begin{array}{l}\text { Purpose(s) } \\
\text { of inquiry }\end{array}$ & Specifics and points of significance \\
\hline \multicolumn{5}{|l|}{ TRES II } \\
\hline $\begin{array}{l}4 \\
\text { Faculty, students, } \\
\text { community } \\
\text { organization } \\
\text { leaders/staff, and } \\
\text { residents who were } \\
\text { members of a } \\
\text { partnership entity }\end{array}$ & $\mid \begin{array}{l}\mathrm{S}, \mathrm{O}, \mathrm{F}, \text { and } \\
\mathrm{R} \rightarrow \\
\text { partnership } \\
\text { itself }\end{array}$ & $\begin{array}{l}\text { Reflection } \\
\& \\
\text { Research }\end{array}$ & $\begin{array}{l}\text { Relationship } \\
\text { development } \\
\& \\
\text { Knowledge } \\
\text { generation } \\
\& \\
\text { Tool } \\
\text { development }\end{array}$ & $\begin{array}{l}\text { - Co-created and piloted TRES II } \\
\text { - Expanded the use of the tool to } \\
\text { include partnership entities explicitly } \\
\text { - Provided information about the } \\
\text { partnership entity and helped to } \\
\text { advance and nuance a collaborative } \\
\text { writing project about its evolution } \\
\text { - Included all relevant SOFAR } \\
\text { categories (no campus administrators } \\
\text { were members of the partnership } \\
\text { entity at the time) }\end{array}$ \\
\hline $\begin{array}{l}5 \\
\text { Doctoral student in } \\
\text { dissertation } \\
\text { research }\end{array}$ & $\mathrm{F} / \mathrm{A} \leftrightarrow \mathrm{O}$ & $\begin{array}{l}\text { Reflection } \\
\& \\
\text { Research }\end{array}$ & $\begin{array}{l}\text { Knowledge } \\
\text { generation }\end{array}$ & $\begin{array}{l}\text { - Involved three faculty/administrator- } \\
\text { community organization staff pairs } \\
\text { - Examined well-established } \\
\text { community-campus relationships in } \\
\text { the discipline of dance, in which } \\
\text { teaching partnerships are rare } \\
\text { - Examined the relationships through } \\
\text { guided conversation to surface their } \\
\text { implicit theories of change } \\
\text { - Integrated some elements of TRES I } \\
\text { with the entirety of TRES II }\end{array}$ \\
\hline $\begin{array}{l}6 \\
\text { Faculty, } \\
\text { administrators, } \\
\text { students, } \\
\text { organization staff, } \\
\text { and community } \\
\text { residents who were } \\
\text { members of an art } \\
\text { collaboration }\end{array}$ & $\mid \begin{array}{l}\mathrm{S}, \mathrm{O}, \mathrm{F}, \mathrm{A}, \\
\text { and } \mathrm{R} \rightarrow \\
\text { partnership } \\
\text { itself }\end{array}$ & Assessment & $\begin{array}{l}\text { Tool } \\
\text { refinement } \\
\text { and } \\
\text { dissemination }\end{array}$ & $\begin{array}{l}\text { - Illustrated emerging approaches to } \\
\text { assessment at a local convening } \\
\text { - Tested accessibility of TRES for } \\
\text { individuals with physical and } \\
\text { cognitive limitations }\end{array}$ \\
\hline $\begin{array}{l}7 \\
\text { Doctoral student in } \\
\text { dissertation } \\
\text { research }\end{array}$ & $\mathrm{O} \leftrightarrow \mathrm{O}$ & Research & $\begin{array}{l}\text { Knowledge } \\
\text { generation }\end{array}$ & $\begin{array}{l}\text { - Expanded context of the tool's use, } \\
\text { adding an international, cross-cultural } \\
\text { dimension and using a co-created, } \\
\text { mixed-methods protocol } \\
\text { - Examined organization-to- } \\
\text { organization relationships, including } \\
25 \text { members from a Cuban, faith- } \\
\text { based civil society organization and } \\
\text { their North American partners }\end{array}$ \\
\hline
\end{tabular}




\begin{tabular}{|c|c|c|c|c|}
\hline Examples & $\begin{array}{l}\text { SOFAR } \\
\text { participants }\end{array}$ & $\begin{array}{l}\text { Mode of } \\
\text { inquiry }\end{array}$ & $\begin{array}{l}\text { Purpose(s) } \\
\text { of inquiry }\end{array}$ & Specifics and points of significance \\
\hline & & & & $\begin{array}{l}\text { - Explored the nature of and perceptions } \\
\text { of interpersonal relationships and how } \\
\text { these affected the performance of } \\
\text { partner organization } \\
\text { - Analyzed how the context of extreme } \\
\text { political enmity between the United } \\
\text { States and Cuba influenced } \\
\text { collaborations at the grassroots level }\end{array}$ \\
\hline $\begin{array}{l}8 \\
\text { Faculty and } \\
\text { administrative } \\
\text { program directors } \\
\text { of global service- } \\
\text { learning (GSL) } \\
\text { programs at a } \\
\text { research university }\end{array}$ & $\begin{array}{l}\mathrm{F}, \mathrm{A}, \text { and } \\
\mathrm{O} \rightarrow \\
\text { partnerships } \\
\text { themselves }\end{array}$ & $\begin{array}{l}\text { Reflection } \\
\& \\
\text { Assessment }\end{array}$ & $\begin{array}{l}\text { Relationship } \\
\text { development } \\
\& \\
\text { Program } \\
\text { capacity } \\
\text { building/ } \\
\text { refinement }\end{array}$ & $\begin{array}{l}\text { - Used by } 3 \text { GSL program directors and } \\
\text { their respective community partners } \\
\text { to examine their own program } \\
\text { planning theories and collaboration } \\
\text { processes as well as the ethos } \\
\text { underlying their practices (e.g. power, } \\
\text { authority) } \\
\text { - Provided TRES as one of several } \\
\text { options for examining partnerships, } \\
\text { which yielded unique information on } \\
\text { conditions under which TRES } \\
\text { contributes to or detracts from } \\
\text { multicultural validity of program } \\
\text { assessment processes and results } \\
\text { - Spurred changes to GSL program } \\
\text { planning among directors and } \\
\text { partners to better align partnership } \\
\text { practice and learning activities with } \\
\text { principles of ethical community } \\
\text { engagement } \\
\text { - Translated to Spanish to broaden } \\
\text { access and utility in diverse contexts }\end{array}$ \\
\hline $\begin{array}{l}9 \\
\text { Administrators at } \\
\text { an SLCE center in } \\
\text { small liberal arts } \\
\text { college }\end{array}$ & $\begin{array}{l}\mathrm{A} \rightarrow \mathrm{O}, \mathrm{F}, \\
\text { and } \mathrm{S}\end{array}$ & $\begin{array}{l}\text { Reflection } \\
\& \\
\text { Assessment }\end{array}$ & $\begin{array}{l}\text { Program } \\
\text { capacity } \\
\text { building/ } \\
\text { refinement }\end{array}$ & $\begin{array}{l}\text { - Explored how TRES might inform } \\
\text { program evaluation and assessment } \\
\text { practices } \\
\text { - Highlighted the complexity and } \\
\text { fluidity of program relationships and } \\
\text { the difficulty of assessing them with a } \\
\text { scale }\end{array}$ \\
\hline
\end{tabular}

The above examples illustrate a number of contexts and ways in which TRES has been used for various purposes and have involved different combinations of individuals/roles across SOFAR. We offer them as illustrations that span types of inquiry (i.e., reflection, assessment, research) with the hope that practitioner-scholars will be motivated to develop their own innovative applications of TRES based on these examples and develop opportunities to explore how TRES might contribute to their work. This could include using TRES, or some other tool, as a basis for improving SLCE relationships and for 
workshops that promote creative thinking and practice about relationships and partnerships. Subsequent sections of this article present lessons learned from these uses and propose additional knowledge sources that can further shape TRES as a tool and expand its use to broader settings.

\section{Lessons Learned Through TRES and Implications for Future Inquiry and Practice}

In addition to generating insights into the complexity of the participants' relationships, these examples have stretched our thinking, sharpened our understanding of the strengths and limitations of TRES, and directed our attention to opportunities for future inquiry (whether in the form of reflection on partnership practices, assessment of partnership quality, or research). Keeping in mind the transformative aspirations of democratic engagement, our collective experience with and reflection on the tool lead us to posit highlevel questions, including: Are transformational relationships also (always? usually?) democratic (i.e., cocreated, asset-based)? If so, under what conditions? If not, what distinguishes an SLCE partnership that is "transformational" from one that is "democratically engaged?" Does the paradigm of democratic engagement add dimensions to previous work on transactional and transformational relationships that need to be conceptualized, operationalized, and investigated? In addition, three themes stand out from the examples above, which warrant consideration as guideposts for designing inquiry into SLCE relationship and partnership practices: support for meaning-making among participants, attention to cultural differences, and sensitivity to pervasive power dynamics.

\section{Support for Meaning-Making Among Participants}

The democratic engagement paradigm prioritizes dialogue as a pathway for learning, growth, and change. Several of the examples above illustrate how TRES (and other such tools) can be integrated into dialogic processes that support individual and collaborative phenomenological meaning-making. In example 1, the scale was incorporated into a broader interview protocol that invited faculty to consider the sources and significance of their responses as well as implications for their relationships. Although not operationalized in that study, example 1 provided a model for future inquiry in which multiple SOFAR stakeholders could complete the scale, consider associated questions about the relationships, and analyze their responses together as a collective reflection and meaning-making activity. In the majority of the uses summarized above (examples $2,4,5,6,8,9$ ), the scale was enhanced with additional questions directed toward shared meaning-making (in some cases as part of broader mixed method, action-inquiry approaches). For instance, in example 5, faculty-administrators and organizational partners used TRES II as a component of a broader conversation to surface the implicit theories of change undergirding their work together. By contrast, in example 9, the administrators used both TRES I and TRES II as stand-alone tools. Reflecting on that experience and reviewing the more expansive approach taken in example 1, they determined that their future uses of the tool would need to incorporate a set of reflective prompts before and after the scale in order to maximize its value for their program. Thus, however valid TRES is as an assessment tool, its utility for practitioner-scholars may often be increased through integrating additional support (e.g., questions, facilitation), particularly when learning and growth are desired goals.

Future inquiry could explore the conditions and design factors under which completion of a tool like TRES, combined with additional supports, leads to clarification of the nature of relationships. Under what conditions does facilitated collective discussion of responses by participants lead to changes in relationships and/or enhanced outcomes? What contextual factors (e.g., pre-established trust, relationship between participants and facilitator, community or campus setting, composition of group) influence the effectiveness of using such tools to improve relationships? For what kinds of relationships (e.g., exploitative, transactional)? Relatedly, future research could examine whether introducing TRES as a mechanism for relationship development provides a buffer against participant transitions (e.g., exiting, dissolution, turnover), thereby resulting in greater stability over time. 


\section{Attention to Cultural Differences}

The far-reaching uses of TRES have surfaced questions regarding the cultural responsiveness of the tool, not only across SOFAR stakeholder categories but also within and across geographic, political, economic, and cultural boundaries. Several uses of TRES (examples 6, 7,8) revealed some limitations when the tool was implemented as a stand-alone in cross-cultural settings and with marginalized populations. TRES proved a challenging instrument to use with some groups (e.g., elders with cognitive impairment, people with limited or no English proficiency, individuals with limited motor ability). Although TRES was designed to minimize the use of academic jargon, some word choices and phrasing were perceived as inaccessible to some users. Alternative forms of administration (e.g., through conversation, focus group) may make the tool more accessible to individuals with limited literacy or mobility. The problem of jargon in TRES was compounded in translation as some constructs were difficult to translate or lacked cultural salience for some respondents (e.g., items focused on identity formation).

Further testing of translated versions of TRES in cross-cultural contexts, with a focus on adapting items and terms according to local linguistic and cultural understandings of constructs such as power, identity, and trust, would help improve its cultural responsiveness and utility. The cross-cultural salience of TRES as a measure of transformational relationships raises broader questions about the content validity of TRES across cultural settings. To what degree do TRES constructs have validity in cultural contexts marked by histories of systemic inequity? Do the items that comprise TRES account for the characteristics of transformational relationships in community-campus relationships in non-democratic or emerging democratic societies? How can tools be developed that have greater flexibility with regard to content, time perspective, context, roles, attributes, and process? How do these factors influence validity and usefulness?

\section{Sensitivity to Pervasive Power Dynamics}

Aspirations for transformational and democratic partnerships invite consideration of the degree to which ownership of inquiry is shared across SOFAR stakeholders. Power is a pervasive dimension of human relationships. Power dynamics are present in the choices practitioner-scholars make to integrate TRES (or any other tools) into their inquiry and practice, including why, how, when, and where they administer it and interpret the responses, not to mention who determines the agenda for inquiry and the direction it will take. In nearly all uses of TRES reviewed above, the impetus came from academics.

The use of the tool among constituencies other than faculty has broadened over the years, engaging more campus administrators and representatives of community organizations (examples 1, 2, 3, 5, 7, 8, 9) although less so students and residents (examples 4 and 6 are exceptions). Simple participation in a study as respondents, however, is not the same as co-creation. This is a challenge noted by the creators of TRES and subsequently echoed by community member respondents themselves. By way of illustration, as a component of a broader investigation of nonprofit partners' perspectives on the impact, integrity, and inclusivity of their engagement with higher education institutions, Williams (2019) asked representatives from community organizations (O) to comment on TRES II as an example of a tool used in SLCE assessment. Recognizing that persons in roles such as theirs had not been involved in its development, they raised concerns regarding the accessibility of some of the language, offered suggestions for more and better uses of visual elements, and highlighted potentially problematic aspects of some of the items (e.g., the implication in "identity formation" as currently expressed, without explanation, that their individual and organizational identities separate from their relationship with a campus were not valued).

Despite increasing the range of voices in uses of TRES, decision-making authority and control over the direction of inquiry rested predominantly in the hands of higher education partners across these examples, a situation that suggests important questions. How are inquiry and practice improved or undermined when initiation comes from a campus rather than being co-generated? What alternative elements, scale items, or tool content might be included in a future iteration of TRES or other tools to enhance shared authority in inquiry, and by what processes might possibilities be collaboratively explored? How might adding one or more "fill in the blank" scale items - so that users might identify 
their own additional relationship domains to explore-illuminate important dynamics unique to a specific relationship?

TRES I and II both attend to questions of relational power but ignore some other types of power (e.g. structural, institutional) relevant to studying the quality of relationships. The use of TRES may have unintended consequences. On the one hand, there is the potential to surface tensions, challenges, and shortcomings that have not been recognized or discussed, which might generate helpful insights. At the same time, some partners may perceive certain responses to be more desirable and as a result fail to disclose their honest assessments of the actual or desired state of their relationships. This risk was illustrated in example 8: Two of the directors, who led programs that provided oral health care to indigenous communities, expressed concern that because access to care was limited in these communities, responses were shaped by a desire to please and not risk alienating institutions that were perceived as sources of critical resources. As this work moves forward, how can research and practice lead to greater understanding of ways to obtain authentic responses?

\section{Summary}

These three lessons learned have, can, and should contribute to the ongoing evolution of how SLCE practitioner-scholars might best think about, inquire into, engage in, and support initiation and improvement of relationships and partnerships. In addition to yielding insights into the complexity of relationships, each use has sharpened our understanding of TRES itself (e.g., strengths, limitations), how it is delivered (e.g., venue, context, purpose, facilitation), and the importance of ancillary tools and processes to help it reach its full potential as a vehicle for reflection, assessment, and research. In this light, our ongoing development of TRES includes, for example, co-creating (with a wider range of SOFAR participants) critical reflection prompts for use before, within, and after the scale for personalized meaning-making of both the responses and the experience of completing it and for turning that learning into action. We also plan to build out support for contextualized facilitation of collaborative uses, with a particular eye to the implications of power dynamics within relationships for the risk-taking associated with such examination of one's own and others' practices. And we see much potential for refining the domains and response options by drawing on recent work on democratic engagement, asset-based orientations to community-campus engagement, and multiple frameworks for "transformation" (e.g., transformational learning) as well as the experience of previous and future users of the tool.

There is also the question of how to know whether and under what conditions TRES (or any other tool) is appropriate to use. No tool has validity independent of its use and context; context and purpose matter in the design, selection, and administration of any tool. TRES provides a sample of domains that may or may not be phenomenologically relevant to the participants in any particular SLCE activity. The potential integration of additional domains in the ongoing development of TRES (or any tool) should be informed by the sense (among members of any SOFAR categories) of whether and how the current set does and does not sufficiently speak to their perspectives on and experiences of relationships and partnerships. TRES II was developed to improve and expand the utility of TRES I, but the choice between the scales should be based on such factors as purpose and constraints. TRES II is not necessarily "better" than TRES I, or vice versa; either might be appropriate for a particular application or study. More fundamentally, it is important to ask in what ways the nature of a scale (e.g., forced choice, minimal explanation of complex items, the need for supplementary support processes in moving from discrete and individualized response options to collaborative interpretation of interconnected ideas and implications) aligns with (or not) the various epistemologies at play in any SLCE relationship and partnership.

There are not only other tools but also other approaches (e.g., focus groups, storytelling) and other conceptual and theoretical frameworks. As one example, Price and colleagues' work on Collaborative Relationship Mapping (ColRM; Price et al., 2016; Wood et al., 2013) grew out of work on SOFAR and TRES but more directly represents participants' own experiential and interpretive impressions of their relationships and partnerships. ColRM combines elements of network analysis and visual mapping to support individuals and groups in examining relationship dynamics at play in SLCE networks. 
Participants map their positionality within and across SOFAR groups and connect how they see themselves within a given relationship with their perceptions of and interactions with others (e.g., roles, communication, decision-making), thereby making visible the tacit assumptions that inform with whom they work and how they work together and surfacing otherwise hidden strengths and tensions in their relationships. ColRM also provides an opportunity to critically examine who is not involved, or not, in participating at optimal levels.

The strengths and shortcomings of all available work, including (but not limited to) TRES, should be compared and contrasted. There are currently few strong tools for inquiring into SLCE relationships and partnerships, and the field will be well served as practitioner-scholars continue this work by developing a variety of alternative approaches. Multiple knowledge sources (e.g., diverse potential users, previous research, various bodies of literature, promising practices, cognate theories) will need to be integrated as will a wide range of cultural perspectives.

\section{Beyond TRES: Emerging Conceptualizations in Partnership Inquiry and Practice}

In this section, we go beyond the microcosm of work to date on TRES to explore possibilities for broadening and deepening inquiry and practice related to relationships and partnerships. Two recent developments can serve as catalysts: (a) a partnership program that chose not to use TRES and (b) the framework of Democratically Engaged Assessment (DEA). Together, they confirm an emerging sense that both the core construct of this work (i.e., relationships/partnerships) and the core process (i.e., inquiry through reflection, assessment, research) are being reconceptualized to align with systems thinking (i.e., attention to such factors as interdependence, complexity, non-linearity, the influence of underlying structures, and the reality of consequences that are not anticipated) and co-creation-both central to the epistemologies and values of democratic engagement. In the remainder of this article, we explore how these implications may influence future inquiry and practice on community-campus relationships and partnerships.

\section{Shifts in Conceptualizing Relationships and Partnerships}

As we have pondered the next chapter of the story of TRES, one particularly important perspective is that of partnerships that seek to enact democratic engagement and are looking for well-aligned processes and tools to support their inquiry and practice. Our critical reflection on TRES as a microcosm for exploring the ongoing evolution of inquiry and practice has included discussion with one such set of partnerships that did not find TRES helpful and chose not to use it. Unpacking the misalignment they identified between the tool and their own experiences and commitments adds significantly to the lessons learned from examination of the examples of how TRES has been used and, in turn, suggests compelling alternative frameworks and approaches for future inquiry and practice.

The Community-Engaged Pathways and Partnerships: A Collective Scholarship Fellows Program (P2) provides the non-use case. Administered by the Institute for Community and Economic Engagement at the University of North Carolina Greensboro, P2 provides funding and professional development for partnership entities to develop sustainable pathways and partnerships over the span of three years. This program is explicitly grounded in three partnership frameworks that collectively point toward a way forward:

1) Partnership Identity. Just as individuals have social identities and groups have organizational identities, Janke (2009) posited that partnership entities can also have identities. Her framework of Partnership Identity "looks beyond personal relationships" (p. 92) and identifies a unified mission, identity as members of a distinct entity, organizational structures that facilitate partnership work, and an expectation to enduring change as defining characteristics. Although dyadic relationships exist within partnership entities that have a partnership identity, this framework provides constructs for inquiry at this higher level of analysis. 
2) Generative Reciprocity. Although reciprocity is a well-established aspiration for relationships and partnerships in SLCE, it has long been imprecisely understood. Dostilio et al. (2012) distinguished three conceptualizations of the term: "exchange (parties benefit), influence (parties impact the work), and generativity (together parties produce systemic change, create new value, and/or undergo transformation in their way of being)" (p. 21). Generativity-oriented reciprocity is informed by critical, indigenous, and ecological perspectives and is aligned with transformation (as distinct from transaction), thereby suggesting distinctive characteristics for inquiry.

3) Collective Leadership. In contrast with earlier dyadic (leader-follower) framings, emerging theories of leadership focus on "how leadership emerges from social interaction and takes many forms .... taking seriously its collective dimensions" (Ospina et al., 2020, p. 444). SLCE partnership work is leadership work, enacted as diverse stakeholders across SOFAR (in dyads, triads, networks, and partnership entities) contribute assets and act together toward shared goals. Collective leadership frameworks can provide constructs that are distinct from those grounded in interpersonal relationships.

Examining this partnership program with an eye toward why TRES did not serve in its context illustrates features in the historical evolution of the tool that may be important to modify or supplement as this work moves forward. In the development of TRES I, SLCE partnerships were framed as interpersonal relationships among individual members of SOFAR that included closeness, equity, and integrity (Bringle et al., 2009). The content of TRES I was heavily influenced by (a) the assumptions and constructs of social psychology and (b) Enos and Morton's (2003) framework of transactional and transformational relationships. When the partnership entity discussed above as a catalyst for developing TRES II expressed interest in using TRES I to reflect on its own transformational dynamics and impacts, the tool was modified from the interpersonal level for application at the partnership entity - primarily through simple shifts in language but not, as we now realize, with sufficient attention to the underlying differences between these two levels.

The evolution from TRES I to TRES II was an important step in expanding inquiry into SLCE relationships and partnerships. That said, critical reflection on the three frameworks that underlie the P2 grant program helped us see more clearly than before that shifting framing language to refer to "the partnership" was incomplete. It has also called attention to the ways other community partners are thinking along the same lines. As one example, Tinkler et al. (2014) documented the insight from community members that quality relationships did not develop simply by working together on projects but rather by recognizing and appreciating the value of the whole that emerges from the union of community and campus stakeholders, a whole distinct from the sum of all parts or parties. Therefore, it is useful to view relationships and partnerships through a systems lens - whether they take the form of dyads, triads, networks, or partnership entities. Ongoing evolution of thinking about, inquiring into, engaging in, and supporting SLCE relationships and partnerships thus needs to be deeply grounded in the nuances of emergent, adaptive systems thinking. Distinguishing between transactional and transformational relationships is still important, but new concepts and measures are needed to look at the "complex configurations of the broader system of relationships bounded by teams, organizations, societies, and so on" (Ospina et al., 2020 p. 445).

As one specific example of bringing P2's perspectives on partnerships to bear, the process of future articulation of constructs (e.g., items in scales) will need to consider the ways in which largely unnuanced domains such as "decision-making" or "contribution of resources" are and are not useful. To date, work on TRES has offered such domains as rough summaries of or proxies for multiple composite underlying issues (e.g., which decisions, in what context, by whom, for what purpose, with what consequences), and in some cases or for some purposes, this may be sufficient. Future research could focus more deeply on any of the domains deemed central to SLCE relationships and partnerships to better understand the role a given domain plays in the processes and outcomes of relationships. Although it may not be clear yet what form these tools take, SLCE practitioner-scholars are in need of and primed to produce tools for inquiring into partnership entities in ways that are cognizant of the complex systems in which they reside: informed by, sensitive to, and themselves embodying adaptability for emergence, interdependent interactivity, and 
the interplay of multiple and evolving perspectives. Future inquiry and practice would benefit from increased engagement with theoretical and conceptual frameworks that illuminate the phenomenologically meaningful dynamics of interacting systems of power, oppression, and collective agency (e.g. critical race theory, organizing theory).

\section{Shifts in Conceptualizing Inquiry}

A growing community around Democratically Engaged Assessment (DEA) seeks to name, support, compile examples of, and contribute to a shift that challenges practitioner-scholars interested in relationships and partnerships to ground future inquiry and practice in such values as full participation, co-creation, and generativity. Participatory forms of inquiry are not new; however, they are not all equal in terms of enacting leveling mechanisms to ameliorate power differentials. Given the dominance of the technocratic paradigm, SLCE practitioners-scholars increasingly aim for, yet still struggle with, transforming existing structures and processes to foster such co-inquiry. The DEA framework (Bandy et al., 2018) is a partial and empowering response. To clarify, although "assessment" is in the title of this body of work, its co-creators explain that "inquiry" - by whatever name - is the process in question. DEA is an exploration of what inquiry and practice might look like when practitioner-scholars acknowledge that the process is always inherently enacting values and when, rather than defaulting to dominant technocratic values, they define and undertake it in ways that explicitly walk the talk of the values of democratic engagement. The Democratically Engaged Assessment White Paper (Bandy et al., 2018) "build[s] the beginnings of a toolkit for putting DEA into practice by exploring how these values can be brought to life in each phase of [inquiry] as well as in the selection and development of [inquiry] approaches and tools" (p. 13). TRES is one of five tools examined in the white paper through the use of specific questions designed to unpack the ways in which any tool enacts democratic values and to guide future enhancements to move tools in this direction.

With the underlying "conviction that democratic deliberation can lead to [inquiry] that [is] well informed as well as culturally and cognitively diverse," DEA "requires structures that institutionalize the possibilities of participation [by] all who affect and are affected by the work in question" (Bandy et al., 2018, p. 18). Transdisciplinarity offers a useful framework on this point. Aligned with the conviction of the democratic engagement paradigm that everyone is a knowledge producer (not only a consumer) and that new understanding emerges through diverse webs of interaction, transdisciplinary inquiry is not limited to the constructs and principles of academic disciplines but rather incorporates a wider range of ways to generate, organize, and steward knowledge. At the root of transdisciplinary inquiry lies the notion that the identification and pursuit of questions are co-created acts of deliberation. In the language of SOFAR, transdisciplinarity explicitly invites - indeed, insists on - the integration of knowledge held by and generated by community members (O and R), students (S), and professional staff (A) as well as faculty $(\mathrm{F})$, regardless of their affinity (or lack of it) with one or more disciplines.

Research can inform the determination of useful and appropriate means of enabling such participation. As the story of TRES demonstrates, this orientation to inquiry and practice is difficult to achieve, especially given the largely technocratic norms and structures that constrain, if not define, academic work on relationships. Although not offering an escape from that reality, another one of the values of democratic engagement-practicability - acknowledges "the reality of the world as it is, cognizant of the power structures and limitations we face" and insists on "navigating those challenges with an eye toward the world we want to bring into being" (p. 28). Thus, another way in which the work of DEA points to future directions for inquiry and practice lies in its exploration of both the tensions involved in shifting toward democratic orientations in a technocratic context and the possibilities for holding those tensions creatively so as to maximize transformation. The global SLCE research community is well positioned to leverage work on DEA so as to contribute to enhanced understanding of the similarities and differences in how this shift in conceptualizing inquiry emerges across international contexts and of the associated implications for relationships and partnerships (Global University Network for Innovation, 2014). 
One of the most pervasive tensions at the heart of this shift in conceptualizing inquiry and practice into SLCE relationships involves the question of what it is that we are interested in better understanding and, in turn, improving. Although there is no doubt that studying community impact is underdevelopedboth as a focus across the inquiry modes of reflection, assessment, and research and as an enacted, not merely rhetorical, priority-SLCE is "in a process of re-balancing its priorities to better encompass change in the world as much as change in students" (see Stanlick et al., 2017 for discussion; p. 141). Future inquiry can pursue questions of community impact and thereby both inform and drive practice.

At the same time, SLCE practitioner-scholars are increasingly highlighting the necessity of focusing inquiry not only on impacts (i.e., results, outcomes) but also, and interrelatedly, on processes and relationships. The co-founder of a national nonprofit focused on neighborhood-level community development, for example, indicated that "the product of our work - in the form of successfully executed community projects - is less a part of our conceptualization of the change we pursue than is the process by which it happens" and acknowledged the "risk of conflating — indeed, displacing - process values and impacts with product values and impacts" (Whitney et al., 2016, p. 88). The Interaction Institute for Social Change (Ogden, 2009) offers, as a framework for expansion beyond a focus only on impact, the RP-R (Results - Process - Relationships) Triangle, insisting that understanding is not complete unless all three categories are encompassed in inquiry. Indeed, community members interviewed in a recent study (Muse, 2018) insisted that democratic partnership work requires that a focus on relationship quality precede a focus on outcomes. They also indicated that, from their perspective, relationships and partnerships are desired outcomes of their work with higher education institutions. The processes that are assessed in TRES and from which the E-T-T nature of relationships is inferred have not to our knowledge been studied with regard to a spectrum of results, which may be proximal or distal, immediate or longterm, and uneven across constituencies (Bringle \& Clayton, 2013). Research is needed to determine the best ways to advance work that aspires to democratic and transformational relationships, processes, and outcomes among individuals, organizations, institutions, and communities. Research can also generate better understanding of how practitioner-scholars can best hold in creative tension the conviction, on the one hand, that the relationships in which we engage are, in and of themselves, meaningful outcomes of the work that merit academic study and, on the other, the need for SLCE to develop evidence-based approaches to examining the tangible outcomes of partnership work (for related discussion see Rubin, 2000).

\section{Conclusion}

The paradox of trying to describe an ever-evolving idea or practice is that new understandings rarely present themselves in complete, recognizably distinct phases. This seems particularly true for inquiry and practice related to SLCE relationship and partnership work. Therefore, we described key developments in the evolution of this work by first pointing to conceptual frameworks that have emerged in the past decade (including older literature that has newfound relevance) and acknowledging the unfinished nature of this developmental process. We described TRES as a tool for the assessment of relationships and as a starting place for critical reflection on community-campus partnerships, and we examined examples of how practitioner-scholars have used TRES in a variety of contexts. After distilling lessons learned from these examples, we discussed implications that transcend TRES. At the heart of our thinking about directions for future inquiry and practice is a turn toward democratic engagement and, in that context, experientially grounded perspectives from the full range of partners, systems thinking, and co-creation. Practitioner-scholars may glean several key takeaways from this article, including conceptual frameworks for relationships and partnerships; the TRES tools, examples of how to implement TRES to reflect on, assess, and enhance the practice of relationships; and directions for future inquiry and practice. There is much to be gained by reflecting on past and current understandings of community-campus relationships and partnerships while also acknowledging forward momentum.

Integrating the full range of SOFAR perspectives is perhaps the single most important commitment that must ground ongoing evolution of inquiry and practice related to partnership work in SLCE. The 
development of TRES to date has, like too much SLCE scholarship, been driven almost exclusively by faculty (F) and SLCE professionals (A), with contributions made through its use by graduate students (S). We have tried to take small steps toward integrating a wider range of voices. Although none of the coauthors directly brings community $(\mathrm{O}, \mathrm{R})$ voices to the writing of this piece, we have sought out such perspectives in each of the three knowledge sources we have incorporated (i.e., users of TRES, other individuals engaged on the ground in partnership practices, SLCE literature) and have drawn on them to shape our thinking about and suggestions for future work. The question of how the evolution of partnership work can best be co-created by all SOFAR constituents is a long-standing one, fraughtwith tensions related not only to processes for opening and maintaining "co-" spaces but also to the motivations, priorities, and purposes at play among the variety of SOFAR participants and their contexts. Thus, the story of TRES serves in this way as a microcosm for examining tensions at the heart of how to think about, inquire into, engage in, and support SLCE partnerships.

We understand that there are other conceptual frameworks and tools relevant to inquiry into and practice of SLCE relationships and partnerships. TRES, however, offers an instructive example of how practitioner-scholarship can expand and deepen over time, especially under conditions of self-critical and appreciative co-inquiry. As Clayton et al. (2010) noted:

It is our hope that these models and tools will help build the capacity of the field to explore .... questions and use what we learn together to enhance practice and, in turn, to generate ever-better questions regarding this important aspect of our work. (p. 19)

We challenge readers to continue pushing the leading edges of this particular dimension of communitycampus engagement, becoming ever more attentive to the emerging possibilities of partnership work and increasingly creative and collaborative in related realms of inquiry. And we invite you to share the stories of the evolution of your own work.

\section{References}

Bandy, J., Price, M. F., Clayton, P. H., Metzker, J., Nigro, G., Stanlick, S., Etheridge Woodson, S., Bartel, A., \& Gale, S. (2018). Democratically engaged assessment: Reimagining the purposes and practices of assessment in community engagement. Imagining America. https://scholarworks.iupui.edu/handle/1805/17729

Bringle, R. G., \& Clayton, P. H. (2013). Conceptual frameworks for partnerships in service learning. In P. H. Clayton, R. G. Bringle, \& J. A. Hatcher (Eds.), Research on service learning: Conceptual frameworks and assessment (Vol. 2B: Communities, institutions, and partnerships, pp. 539-571). Stylus.

Bringle, R. G., Clayton, P. H., \& Price, M. F. (2009). Partnerships in service-learning and civic engagement. Partnerships: A Journal of Service-Learning \& Civic Engagement, 1(1). http://libjournal.uncg.edu/prt/article/view/415/228

Bringle, R. G., \& Hatcher, J. A. (2002). University-community partnerships: The terms of engagement. Journal of Social Issues, 58(3), 503-516. https://doi.org/10.1111/1540-4560.00273

Clayton, P. H., Bringle, R. G., \& Hatcher, J. A. (Eds.). (2013). Research on service learning: Conceptual frameworks and assessment (Vol. 2B: Communities, institutions, and partnerships). Stylus.

Clayton, P. H., Bringle, R. G., Senor, B., Huq, J., \& Morrison, M. (2010). Differentiating and assessing relationships in service-learning and civic engagement: Exploitive, transactional, and transformational. Michigan Journal of Community Service Learning, 16(2), 5-21. http://hdl.handle.net/2027/spo.3239521.0016.201

Clayton, P. H., Janke, E. M., Hess, G., \& Bringle, R. G. (2009). Transformational Relationship Evaluation Scale, II [Unpublished document]. PHC Ventures.

Cruz, N., \& Giles, Jr., D. E., (2000). Where's the community in service-learning research? Michigan Journal of Community Service Learning, Special issue(1), 28-34. http://hdl.handle.net/2027/spo.3239521.spec.104 
Dostilio, L. D., Brackmann, S. M., Edwards, K. E., Harrison, B., Kliewer, B. W., \& Clayton, P. H. (2012). Reciprocity: Saying what we mean and meaning what we say. Michigan Journal of Community Service Learning, 19(1), 17-32. http://hdl.handle.net/2027/spo.3239521.0019.102

Dostilio, L. D. (2014). Democratically engaged community-university partnerships: Reciprocal determinants of democratically oriented roles and processes. Journal of Higher Education Outreach and Engagement, 18(4), 235-244. https://openjournals.libs.uga.edu/jheoe/article/view/1159/1158

Dostilio, L. D. (Ed.). (2017). The community engagement professional in higher education: A competency model for an emerging field. Stylus.

Enos, S., \& Morton, K. (2003). Developing a theory and practice of campus community partnerships. In B. Jacoby (Ed.), Building partnerships for service-learning (pp. 20-41). Jossey-Bass.

Global University Network for Innovation. (2014). Higher education in the world 5. Knowledge, engagement \& higher education: Contributing to social change. Palgrave.

Jacoby, B. (2013). Student partnerships in service learning. In P. H. Clayton, R. G. Bringle, \& J. A. Hatcher (Eds.), Research on service learning: Conceptual frameworks and assessment (Vol. 2B: Communities, institutions, and partnerships, pp. 599-618). Stylus.

Janke, E. M. (2009). Defining characteristics of partnership identity in faculty-community partnerships. In B. Moely, S. Billig, \& B. Holland (Eds.), Creating our identities in service-learning and community engagement (pp. 75-101). Information Age Publishing.

Janke, E. M. (2013). Organizational partnerships in service learning. In P. H. Clayton, R. G. Bringle, \& J. A. Hatcher (Eds.), Research on service learning: Conceptual frameworks and assessment (Vol. 2B: Communities, institutions, and partnerships, pp. 573-598). Stylus.

McReynolds, A., \& Shields, E. (2015). Diving deep in community engagement: A model for professional development. Campus Compact.

Mashek, D., Cannaday, L. W., \& Tangney, J. P. (2007). Inclusion of community in self scale: A singleitem pictorial measure of community connectedness. Journal of Community Psychology, 35, 257275. https://doi.org/10.1002/jcop.20146

Muse, S. (2018). Exploring the community impact of community-university partnerships [Doctoral dissertation, University of Denver]. https://digitalcommons.du.edu/etd/1415/

Ogden, C. (2009, November 5). Means and ends [Blog post]. http://interactioninstitute.org/means-andends/

Ospina, S. M., Foldy, E. G., Fairhurst, G. T., \& Jackson, B. (2020). Collective dimensions of leadership: Connecting theory and method. Human Relations, 73(4), 441-463. https://doi.org/10.1177/0018726719899714

Price, M. F., Napier, P., Wood, E., \& Officer, S. D. (2016, October 6-8). Collaborative Relationship Mapping (ColRM): A tool for building bridges, relationships, and capacity. National Conference of Imagining America: Artists and Scholars in Public Life, Milwaukee, WI, United States.

Rubin, V. (2000). Evaluating university-community partnerships: An examination of the evolution of questions and approaches. Cityscape: A Journal of Policy Development and Research, 5(1), 219-230. https://www.jstor.org/stable/20868505

Saltmarsh, J., Hartley, M., \& Clayton, P. H. (2009). Democratic engagement white paper. New England Resource Center for Higher Education. http://repository.upenn.edu/gse pubs/274

Stanlick, S. E., Kniffin, L. E., Clayton, P. H., Zlotkowski, E., \& Howard, J. (2017). Urgency and opportunity in difficult times: Elevating voices and widening the circle of SLCE leadership. Michigan Journal of Community Service Learning, 23(2), 138-144. http://dx.doi.org/10.3998/mjcsloa.3239521.0023.211

Tinkler, A., Tinkler, B., Hausman, E., \& Strouse, G. T. (2014). Key elements of effective service-learning partnerships from the perspective of community partners. Partnerships: A Journal of ServiceLearning \& Civic Engagement, 5(2), 137-152.

https://libjournal.uncg.edu/index.php/prt/article/view/944 
Wasserman, S., \& Robins, G. (2012). Social network research: The foundation of network science. In H. Cooper, P. M. Camic, D. L. Long, A. T. Panter, D. Rindskopf, \& K. J. Sher (Eds.), APA handbooks in psychology:: APA handbook of research methods in psychology (Vol. 3. Data analysis and research publication, pp. 451-469). American Psychological Association. https://doi.org/10.1037/13621-023

Whitney, B. C., Muse, S., Harrison, B., Edwards, K. E., \& Clayton, P. H. (2016). Learning from and with community organizations to navigate the tensions of democratic engagement. Michigan Journal of Community Service Learning, 23(1), 85-90. http://dx.doi.org/10.3998/mjcsloa.3239521.0023.108

Williams, J. M. (2019). Fitting into the bigger picture: Community engagement efforts among community nonprofit organizations and institutions of higher education through the perspectives of nonprofits [Doctoral dissertation, West Chester University of Pennsylvania]. Digital Commons. https://digitalcommons.wcupa.edu/all doctoral/50

Wood, E., Price, M. F., Kryder-Reid, E., \& Officer, S. D. (2013). Exploring and mapping the capacity for sustained engagement in a community-university partnership [Unpublished manuscript]. IUPUI Museum Studies Program and the IUPUI Center for Service and Learning.

\section{Acknowledgments}

We express our gratitude to the community of SLCE practitioner-scholars, other colleagues, and participants in TRES-related activities who have engaged with us over the past decade in the work we share here: TRES respondents for sharing their time and invaluable insights with us; Emily Janke and George Hess for collaborating on the development of TRES II; conference session participants for offering feedback on TRES II (2020 North Carolina Campus Compact's Pathways to Achieving Civic Engagement Conference concurrent session and 2018 Imagining America conference workshop); Odette Aguirre, Sara Alamdari, Jennifer Custer, Starla Hart, Julie Hatcher, Tammi Hellwig, Jenny Huq, Carmen Luca-Sugawara, Mary Morrison, Jim Mulholland, Bryanne Senor, Jeff Steele, Sanja Vuković-Č́ović, Elee Wood, and members of Imagining America's Assessing Practices of Public Scholarship (APPS) research group for their support of work on TRES and their participation in this process of co-inquiry; and Alexandra TenBarge for refining SOFAR graphics.

\section{About the Authors}

Lori Kniffin is an assistant professor in the Department of Leadership Studies at Fort Hays State University (Hays, Kansas, USA).

Jasmina Camo-Biogradlija is a project manager with the Education Policy Initiative at the University of Michigan (Ann Arbor, MI, USA).

Mary F. Price is director of faculty development in the Center for Service and Learning at Indiana University Purdue University Indianapolis (Indianapolis, IN, USA).

Emily Kohl is the special projects coordinator at Rockbridge Area Relief Association (Lexington, VA, USA).

Alessandra Del Conte Dickovick is associate director of community-based learning at Washington and Lee University (Lexington City, VA, USA).

Jamie Williams is associate director of community service-learning at James Madison University (Harrisonburg, VA, USA).

Jamie Goodwin is an assistant professor in the Department of Humanitarian and Disaster Leadership at Wheaton College (Wheaton, IL, USA).

Kristi V. Johnson is an assistant professor and director of dance at North Carolina Central University and founder of the nonprofit Triangle Dance Project (Durham, NC, USA). 
Patti H. Clayton is a practitioner-scholar and consultant (PHC Ventures) and a senior scholar with the IUPUI Center for Service and Learning.

Robert G. Bringle is chancellor's professor emeritus of psychology and philanthropic studies and a senior scholar in the IUPUI Center for Service and Learning.

Correspondence concerning this article should be addressed to Patti H. Clayton at patti.clayton@curricularengagement.com. 